\title{
MONTE CARLO METHOD AND APPLICATION IN @RISK SIMULATION SYSTEM
}

\author{
Gabriela Ižaríková \\ TU of Košice, Faculty of Mechanical Engineering, Institute of Special Technical Sciences, Department of Applied \\ Mathematics and Informatics, Letná 9, 04200 Košice, e-mail: gabriela.izarikova @ tuke.sk \\ Peter Trebuňa \\ TU of Košice, Faculty of Mechanical Engineering, Institute of Technology and Management, Department of Industrial \\ Engineering and Management, Nemcovej 32,04200 Košice, e-mail: peter.trebuna@tuke.sk
}

\begin{abstract}
Keywords: simulation model, Monte Carlo method, simulation system, design
Abstract: The article is an example of using the software simulation @ Risk designed for simulation in Microsoft Excel spread sheet, demonstrated the possibility of its usage in order to show a universal method of solving problems. The simulation is experimenting with computer models based on the real production process in order to optimize the production processes or the system. The simulation model allows performing a number of experiments, analysing them, evaluating, optimizing and afterwards applying the results to the real system. A simulation model in general is presenting modelling system by using mathematical formulations and logical relations. In the model is possible to distinguish controlled inputs (for instance investment costs) and random outputs (for instance demand), which are by using a model transformed into outputs (for instance mean value of profit). In case of a simulation experiment at the beginning are chosen controlled inputs and random (stochastic) outputs are generated randomly. Simulations belong into quantitative tools, which can be used as a support for a decision making.
\end{abstract}

\section{Introduction}

A simulation model in general is presenting modelling system by using mathematical formulations and logical relations. In the model is possible to distinguish controlled inputs (for instance investment costs) and random outputs (for instance demand), which are by using a model transformed into outputs (for instance mean value of profit). In case of a simulation experiment at the beginning are chosen controlled inputs and random (stochastic) outputs are generated randomly [1]. Simulations belong into quantitative tools, which can be used as a support for a decision making. Their application in practice cannot be done without computer support and specialized software products [2]. For simulations is possible to use a basic tabular processor as for example Microsoft Excel [3]. In the following part is used simulation software Risk, suitable mainly for simulations in the tabular processor Microsoft Excel.

@RISK performs risk analysis using Monte Carlo simulation to show how many possible outcomes in a spread sheet model exist and tells how the likelihood they might occur is. It mathematically and objectively tracks many different possible future scenarios and assess the probabilities and risks associated with each different one. This means that it gives an assessment which risks to take and which ones to avoid, allowing for the best decision making under uncertainty [4].

\section{Monte Carlo method}

Monte Carlo method is a simulation numeric method, which can provide at least probabilistic results in case those classical calculations are too complex, too long or even not possible to compute. It is a stochastic method, because when searching for a result is used probabilistic number of modelled random variables statistical estimates of their characteristics [5].

The method is based on multiple irritation of random process. Realization of probabilistic variables can be achieved by generating of random numbers, uniformly distributed on interval $(0,1)$, which are subsequently by suitable transformation transformed into random numbers with desirables distribution. Random numbers are possible to generate by several ways: mechanic generators, physical generators. It is possible to distinguish random and pseudorandom numbers. By using of Monte Carlo method are estimated statistic distribution based on a huge number of random choices from given distribution [5]. Simulation is resource for increase quality, innovation and prosperity [6], [7]. This system, method will used in @ Risk simulation system [8].

\subsection{Application add-on @RISK}

After running program @ Risk and Microsoft Excel in the top menu of Excel is shown option depicted in the Fig. 1.

Random inputs of model are generated by using addon @ Risk in the top menu in folder "Define Distribution", 


\section{MONTE CARLO METHOD AND APPLICATION IN @RISK SIMULATION SYSTEM}

Gabriela Ižaríková; Peter Trebuňa

in option for discrete and continues probability distribution- Fig. 3. and Fig. 4.

For example it can be defined normal distribution with a mean value 10 and standard deviation $2 \mathrm{~N} \approx(10,2)$. It is possible to click on the icon "Normal" (Fig. 2) window appears (Fig. 3) In the middle is a graphical representation of normal distribution, on the left can be added mean value and standard deviation and on the right are depicted descriptive statistics. The second possibility is generating of random inputs is to write function directly into a cell for normal distribution it is "RiskNormal (mean value, standard deviation)".

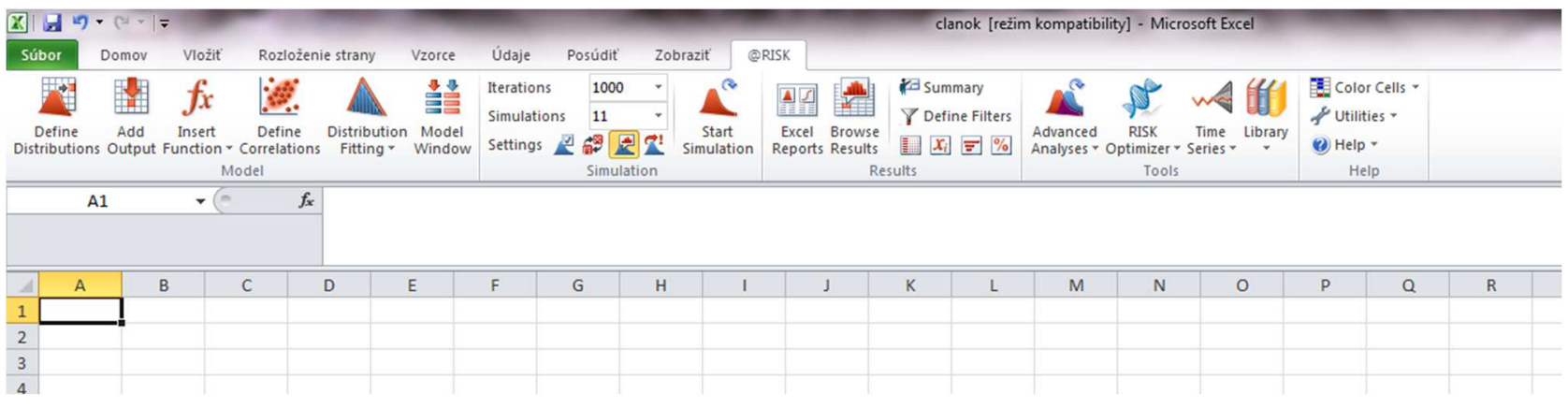

Figure 1 Toolbar - menu for add-on @ Risk

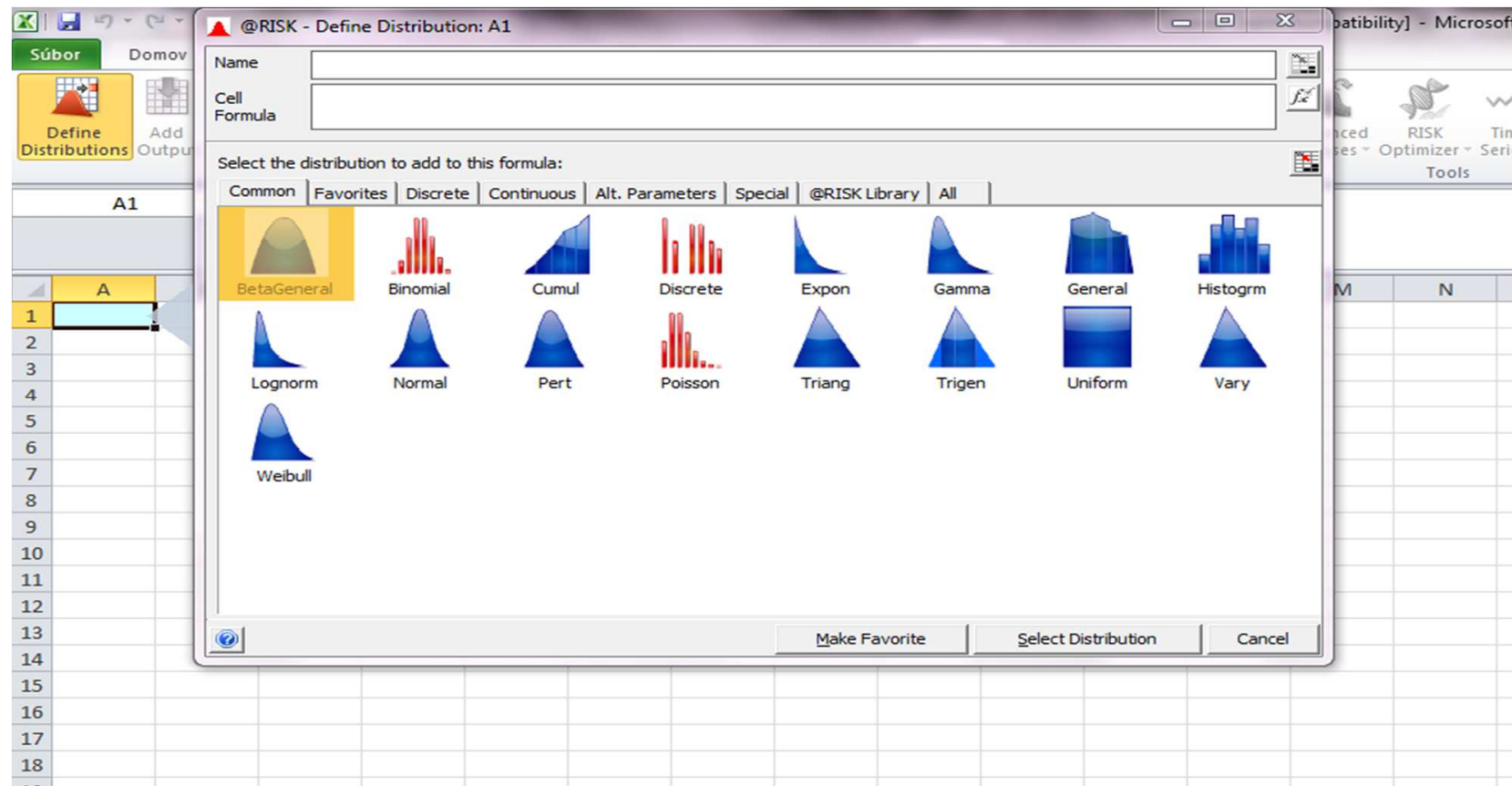

Figure 2 @Risk simulation system and definition of distribution function 
MONTE CARLO METHOD AND APPLICATION IN @RISK SIMULATION SYSTEM

Gabriela Ižaríková; Peter Trebuňa

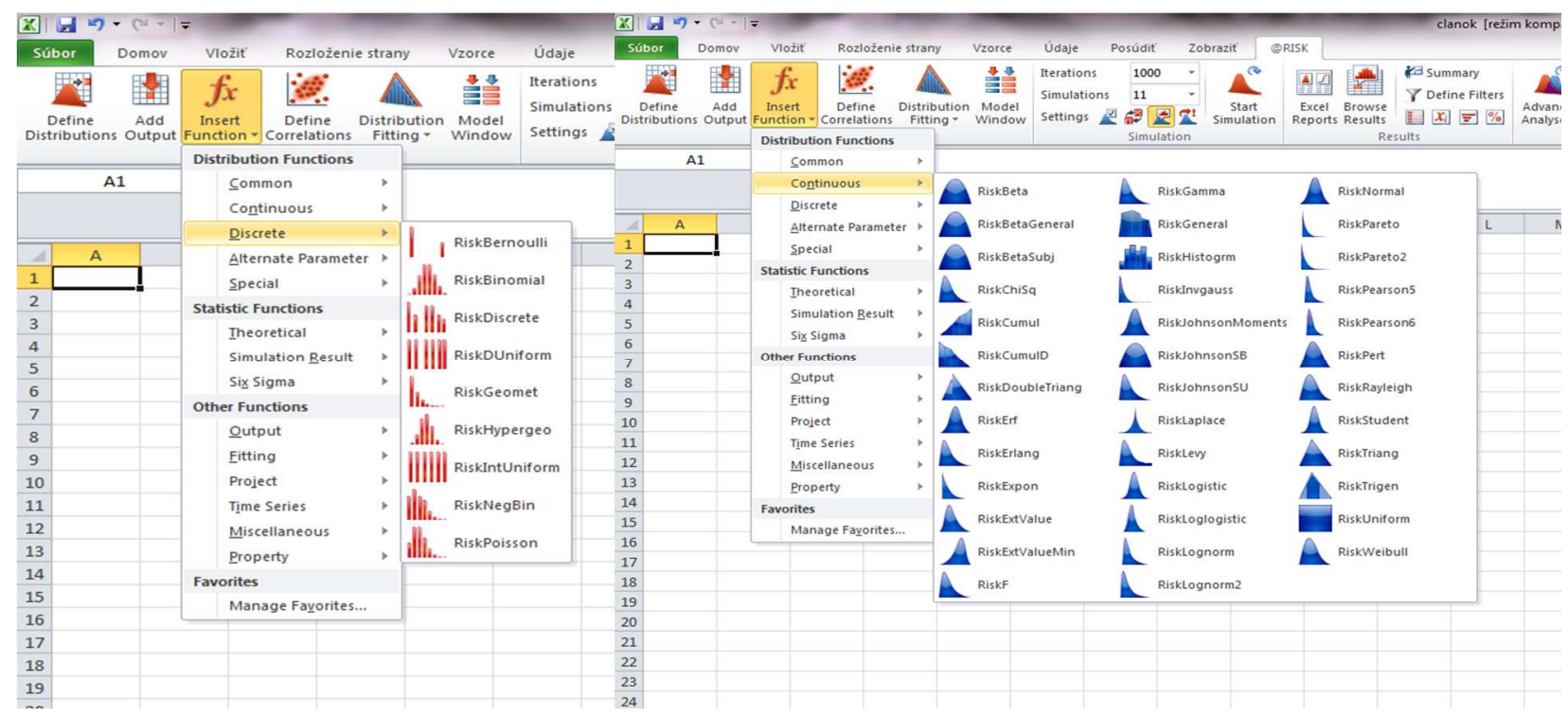

Figure 3 @Risk simulation system, option probability distribution

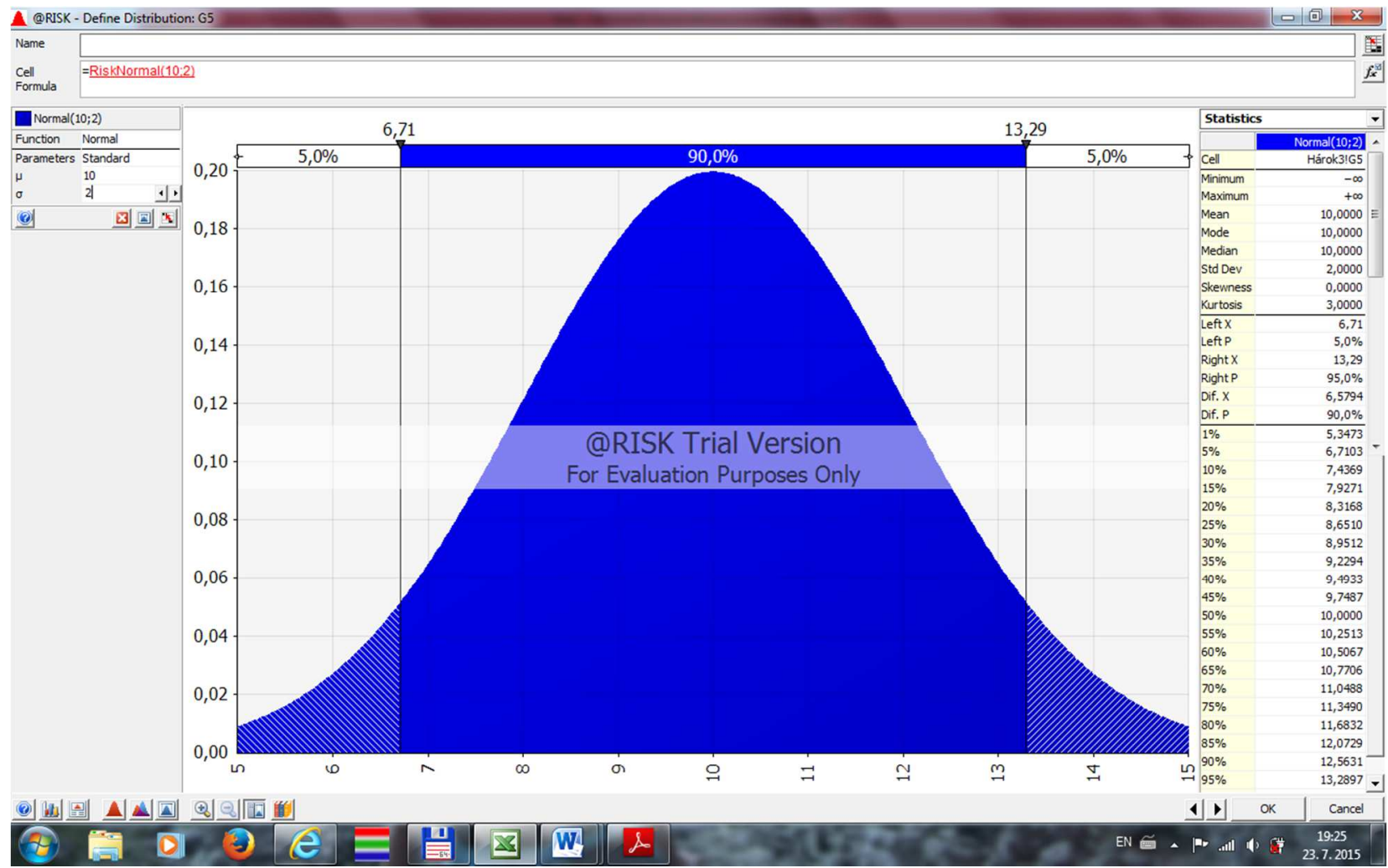

Figure 4 @ Risk simulation system, definition of normal distribution

Design of simulation model by using of add-on @Risk :

- Define probabilistic distribution for a random inputs, it means generating of observations of a random inputs (for example by using function @ Risk).

- In a simulation model is chosen a cell representing output of model (output cell). Add-

\section{$\sim 3 \sim$}


MONTE CARLO METHOD AND APPLICATION IN @RISK SIMULATION SYSTEM

Gabriela Ižaríková; Peter Trebuňa

on @ Risk calculates automatically descriptive statistics for output model and generate also their graphical representation.

- For different values of variables is possible by using function „RiskSimTable“ run the simulation several times and subsequently compare results and choose the best value of crucial variables.

In the next section is represented construction of simulation model on a concrete example: at the beginning of a month is necessary to add inventory of given product, which purchasing price is 3 eur/piece and selling price 5 eur/piece, in case that this product is not sold until $20^{\text {th }}$ day of the month is sold in discount for 2 eur/piece. Demand for this product is random with discrete distribution in Table 1. The task is to construct a simulation model based on the given order.

\section{Construction of simulation model:}

A random input means demand, which is given by discrete probability distribution. In Table 1, in cell A11 is defined by function - ,=RiskDiscrete(D3:D7;E3:E7)“.
Output of the model, which is a profit (lost) in cell E11 and is given by relation ,,=B11-C11-D11“ (profit = salescosts overestimation - cost of buying). This formula can be changed with add-on, by setting on cell E11, in the top menu click on the option "AddOutput", validate it with the fuction in the cell E11 and change on "RiskOutput()+B11-C11-D11".

In the next step is set setting (number of irritation for example on 100) simulation and run simulation. By using @ Risk function "RiskSimTable" it is possible to compare descriptive statistics for different values cotrolled inputs into model, ,=RiskSimTable(B14:L14)“.

The function RiskSimTable makes possible to run several simulations for different values of controlled inputs, in this case 11 times evaluate thousand values of profit (lost). In this section B14:L14 are shown different values of controlled input according to amount of order. Number of irritation 1000 and number of simulation 11 is set on top menu@Risk.

Function for a calculation of descriptive statistics are inserted thought top menu @ Risk - Insert Function Simulation Result - RiskMean, RiskStdDev, RiskMax,

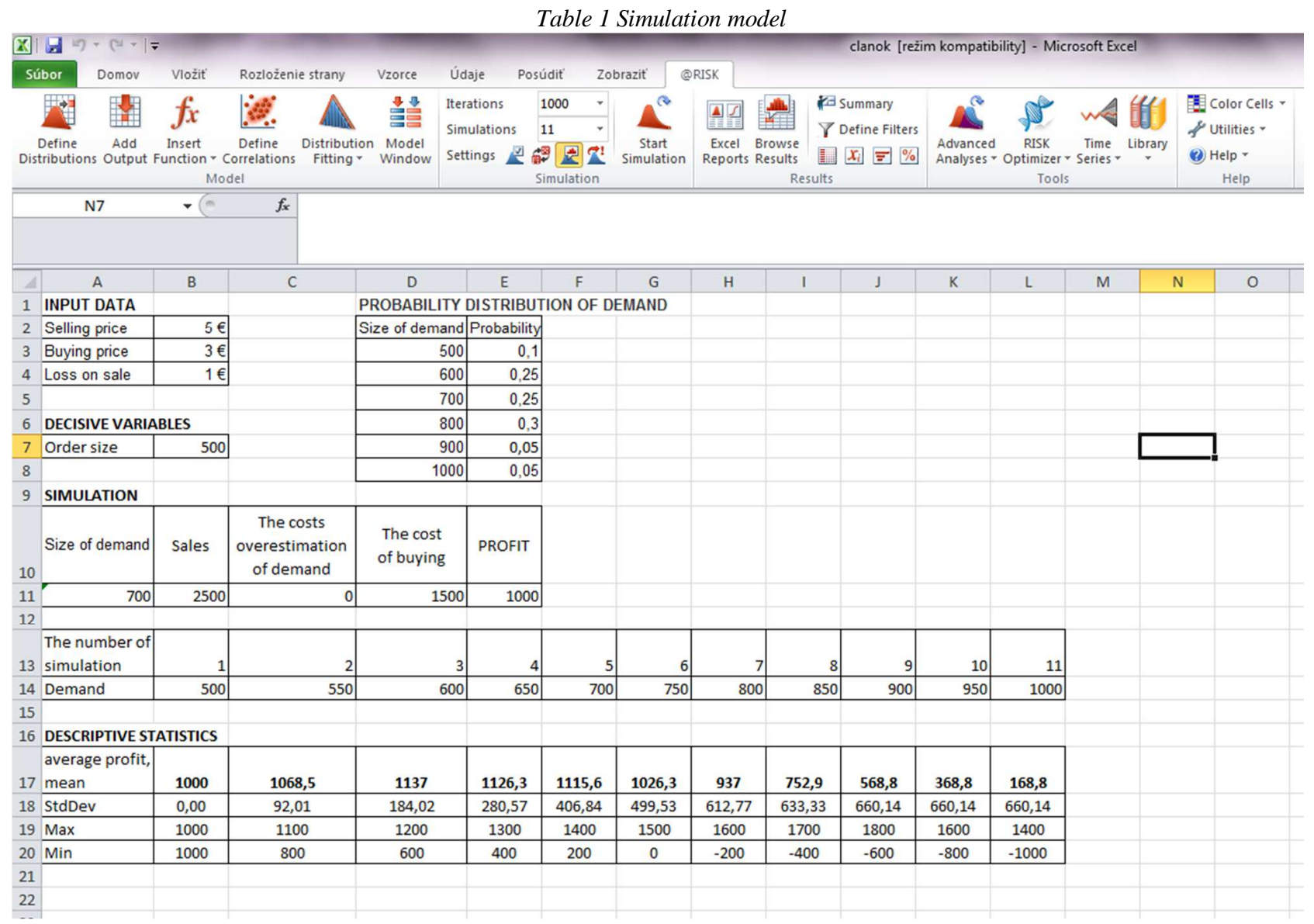


MONTE CARLO METHOD AND APPLICATION IN @RISK SIMULATION SYSTEM

Gabriela Ižaríková; Peter Trebuňa

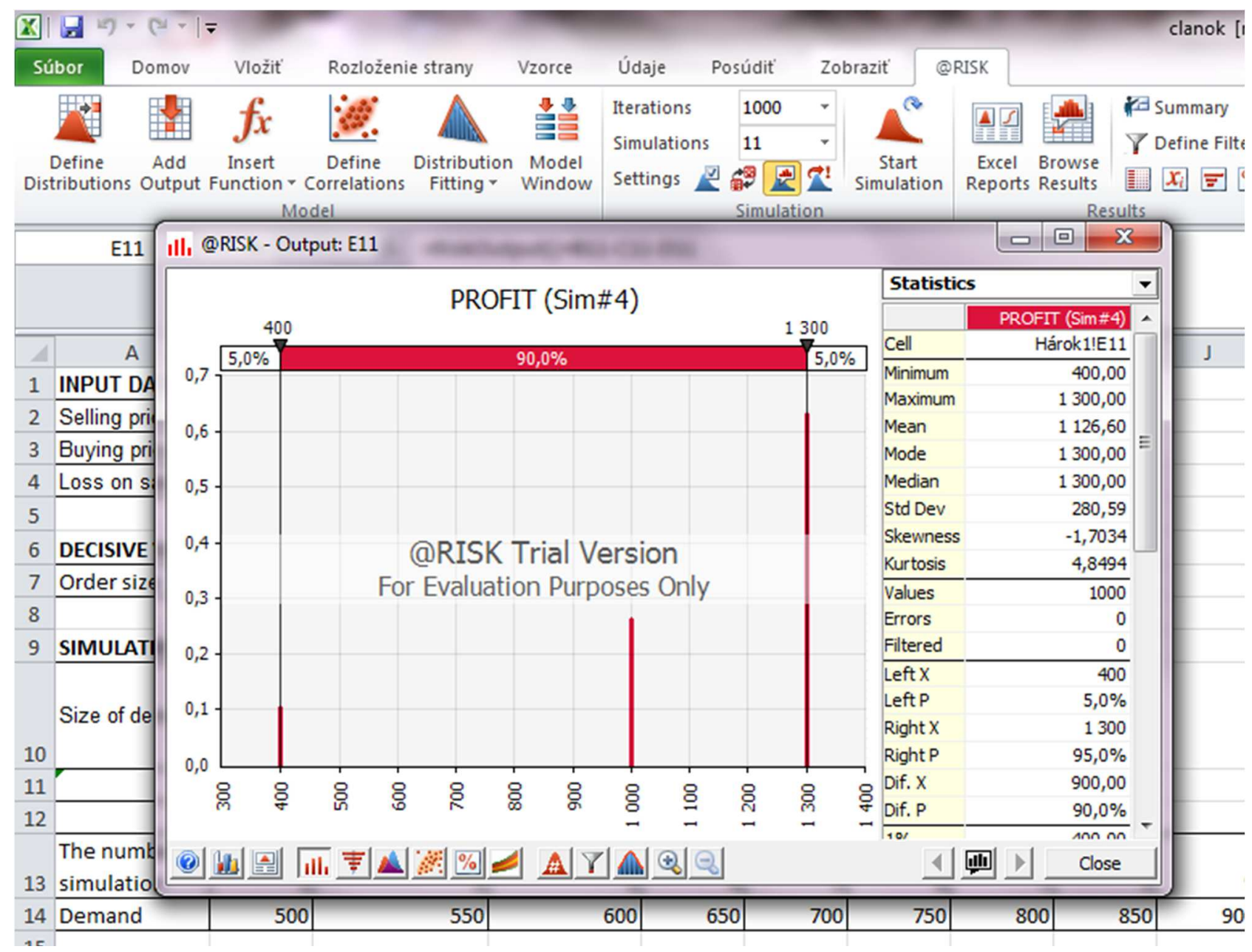

Figure 5 @Risk simulation system, results of simulation (number 4)

RiskMin. When inserting function of descriptive statistics order number of simulations is used, in a first row - Data source - address of output E11 is fixed in a second row - Sim - address of order number is not fixed. Subsequently these functions can be copied into the cells B17:B20 into C17:L20.

The simulation can be run thought top menu @ Risk Start Simulation, after running are depicted in Excel sheet values of given function and simultaneously is shown window with values of different descriptive statistics together with their graphical representation (Fig. 5).

The overview table of results from all simulations is in the Fig. 6. After creating of simulation model and comparing results of simulation the highest risk is for the order of 600 pieces. 
MONTE CARLO METHOD AND APPLICATION IN @RISK SIMULATION SYSTEM

Gabriela Ižaríková; Peter Trebuňa

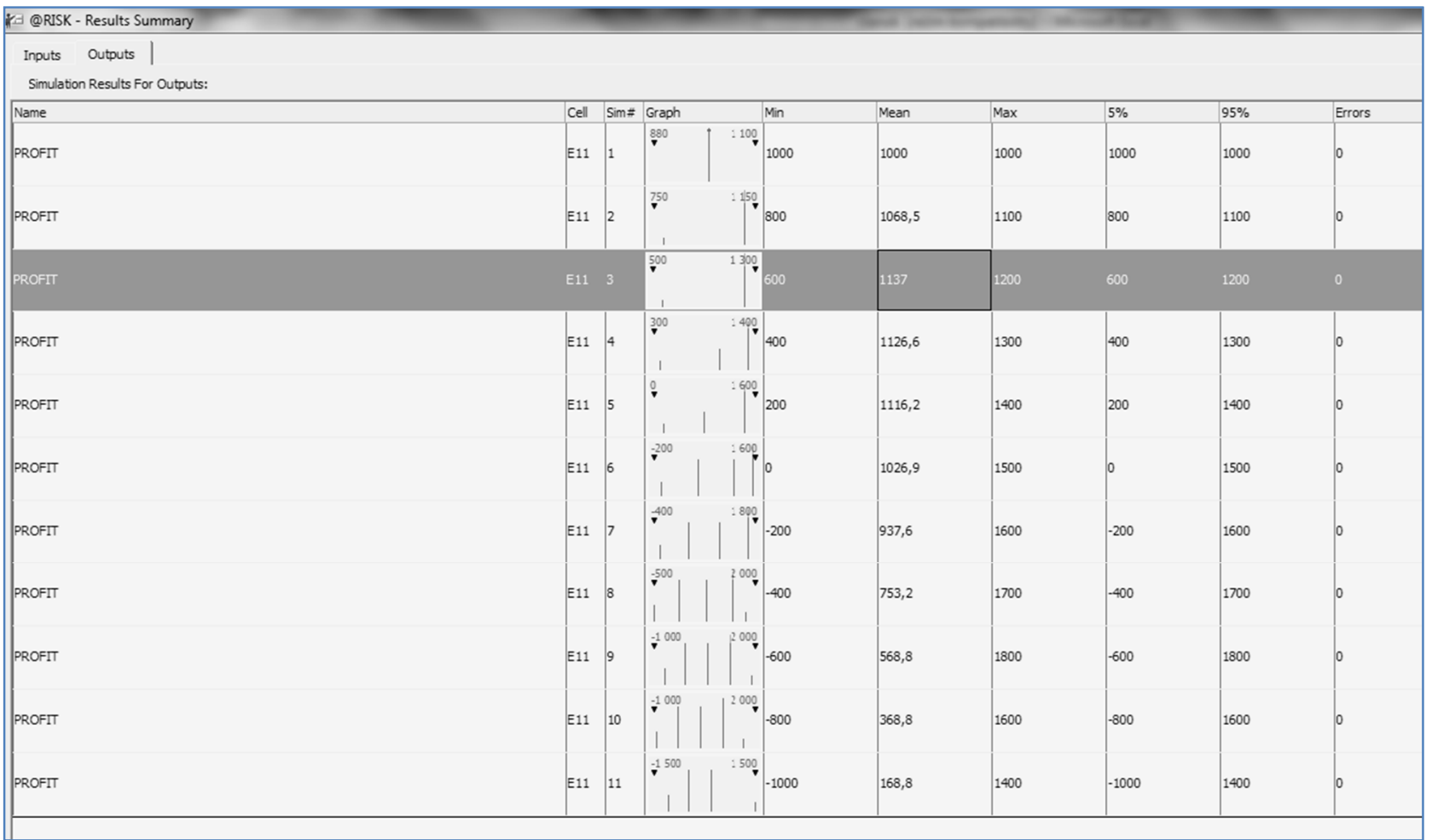

Figure $6 @$ Risk simulation system, table of the simulation results

\section{Conclusions}

The article is an example of using the software simulation@Risk designed for simulation in Microsoft Excel spreadsheet, demonstrated the possibility of its usage in order to show a universal method for problem solving. A simulation is an important and has a stable place in the production process and also in business practice. It is not a tool to solve all the problems, but could be used to quickly optimize and improve. In this paper, a simulation model is assembled with add-ons @ Risk the construction of the simulation model presented concrete examples. After the defection simulation and evaluation of results can determine the size of the order.

\section{Acknowledgement}

This article was created by implementation of the grant project KEGA 004TUKE-4/2013 "Intensification of modelling in teaching II. and III. degree in the field of study 5.2.52 Industrial Engineering ".

\section{References}

[1] NELSON, B. L.: Stochastic Modeling: Analysis and Simulation, McGraw-Hill, 1995.

[2] NEZBEDA, I. a kol.: Úvod do počítačových simulací. Metody Monte Carlo, Karolinum UK Bratislava, p.204, 2003. (original in Slovak)

[3] PEKÁR, J.: Softvérová podpora rozhodovania $\mathrm{v}$ prostredí Microsoft Excel, EKONOM Bratislava, 2010. (original in Slovak)

[4] TREBUŇA, P. a kol.: Modelovanie v priemyselnom inžinierstve, TUKE, p.195, 2015. (original in Slovak)

[5] STRAKA, M.: Diskrétna a spojitá simulácia v simulačnom jazyku EXTEND [online], Košice: TU FBERG, Edičné stredisko/AMS. 2007. (original in Slovak)

[6] SZABO, S., FERENCZ, V., PUCIHAR, A.: Trust, Innovation and Prosperity. In: Quality Innovation Prosperity, Kvalita Inovácia Prosperita, Vol. XVII, No. 2, pp. 1-8, 2013.

[7] CHMELÍKOVÁ, G., BOŽEK, P., HRDLIČKOVÁ, Z.: Multimedia Applications - Efficient Tool for Students and Teachers. In ICT for Language Learning, 4th International Conference, Florence, p. 5., 2011.

[8] www.palisade.com

\section{Review process}

Single-blind peer reviewed process by two reviewers. 